Thorax, 1980, 35, 675-679

\title{
Effect of an inhaled antihistamine on exercise-induced asthma
}

\author{
J P R HARTLEY AND S G NOGRADY
}

From the Asthma Research Unit, Sully Hospital, Sully, and the Department of Tuberculosis and Chest Diseases, Welsh National School of Medicine, Llandough Hospital, Nr Penarth, South Glamorgan

ABSTRACT The ability of the $\mathrm{H}_{1}$ receptor antagonist clemastine to prevent exercise-induced asthma (EIA) has been studied in 10 adult asthmatic subjects. Exercise was performed for eight minutes on a cycle ergometer on two occasions on each of two days. The first test each day was without premedication and the second was preceded by inhalation of $0.05 \%$ clemastine or saline placebo given single blind in random order. Ventilatory function was assessed by serial measurements of peak expiratory flow rate (PEFR) and forced expiratory volume in one second (FEV 1 ). All four tests for each patient were closely matched in terms of oxygen uptake and total ventilation which were monitored throughout exercise. The response to exercise after clemastine or placebo has been compared both directly and in terms of the degree of protection afforded against EIA compared with the initial test on the same day. Clemastine was significantly better

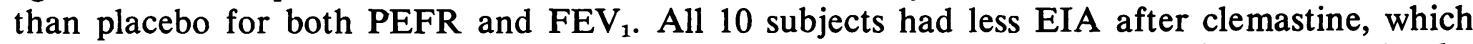
suggests an important role for histamine in its production. Other mechanisms may also be involved to a variable degree in different individuals.

Although much has been learned about the mechanisms of asthma little is known of the immediate cause of increased airways obstruction which occurs in many asthmatic individuals after a brief period of exertion.

Recent work has related exercise-induced asthma (EIA) to hyperventilation and subsequent airway cooling, although it is not clear whether this would act primarily on vagal irritant receptors $^{1}$ or whether it might have a direct effect on mast cells leading to the release of active mediators such as histamine. ${ }^{2}$

We have investigated the role of histamine by the use of a specific $\mathrm{H}_{1}$ receptor blocking agent, clemastine, having previously shown that this antihistamine, given by aerosol inhalation, is a bronchodilator and can inhibit histamine-induced bronchoconstriction. ${ }^{34}$

\section{Methods}

Fifteen patients with stable bronchial asthma gave their informed consent to the study. All had pre-

Address for reprint requests: Dr JPR Hartley, Asthma Research Unit, Sully Hospital Sully, South Glamorgan. viously been shown to have exercise-induced asthma (fall in peak expiratory flow rate, PEFR, or forced expiratory volume in one second, $\mathrm{FEV}_{1}$, of $>15 \%$ after exercise).

Patients performed two exercise tests separated by two hours on each of two study days. The initial test on each day was used to confirm that a similar degree of exercise asthma was present. If the fall in PEFR or FEV 1 was $<15 \%$ after the first test, the subject was asked to attend on another occasion, or was withdrawn from the study. If, in addition, at the second visit, the fall

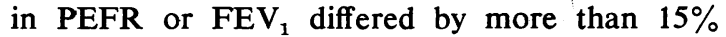
from that at the first, then that individual's response to exercise was considered too variable and he was not included in the study.

Ten patients were considered to have reproducible EIA by the criteria outlined above, and their results form the basis of this report. Their mean age was 35 years (range $24-45 \mathrm{yr}$ ) and six were male. Nine patients had positive skin prick tests to two or more common allergens. No drugs were permitted within 12 hours of exercise testing, with the exception of oral or inhaled corticosteroids (four patients). No patient had taken antihistamines within four weeks of the study. 
Thirty minutes after the initial control exercise test, patients inhaled $1.0 \mathrm{ml}$ of either $0.05 \%$ clemastine fumarate or normal saline from a disposable Hudson nebuliser. The agents were administered single blind in random sequence for the two study days. Ninety minutes later measurements of ventilatory function were made and the second exercise test performed.

Exercise tests were carried out on an electromagnetically braked cycle ergometer (Lode) and consisted of eight minutes of steady-state submaximal exercise as previously described. ${ }^{56}$ The work load was sufficient to raise the heart rate during the last minute of exercise to approximately $80 \%$ of the age-predicted maximum. ${ }^{7}$ Oxygen uptake was calculated at half-minute intervals by entering the results of expired gas analysis and inspired ventilation volume into a programmed calculator $^{5}$ and a graph of total oxygen uptake against time plotted. Subsequent exercise tests were standardised by matching oxygen uptake to within $5 \%$ by adjusting the ergometer setting as exercise progressed. The tests were carried out in a laboratory whose temperature ranged from $20-24^{\circ} \mathrm{C}$. The humidity of the inspired air was not measured or controlled.

The response to exercise was assessed by taking the best of three readings of PEFR (Wright peak flow meter) and $\mathrm{FEV}_{1}$ (Vitograph dry wedge spirometer). Measurements were made five minutes and immediately before exercise, and the mean of these values used as the baseline. They were repeated immediately after exercise and at five minute intervals thereafter for 30 minutes. Predicted normal values for both indices have been taken from Cotes. ${ }^{8}$

Results have been analysed by comparing the maximum falls in PEFR and FEV $_{1}$ after the second exercise test at each visit. Student's $t$ test for paired samples has been performed on $\log _{e} a / b$ where $a$ is the lowest value of PEFR or FEV after exercise and $b$ is the value before exercise. ${ }^{5}$

The data have also been examined by calculat- ing a "\% protection index" for each test day. ${ }^{910}$ 을 This represents the maximum \% fall in PEFR or $\frac{\bar{\sigma}}{\overline{0}}$ $\mathrm{FEV}_{1}$ after the first exercise test each day, minus $\vec{\sigma}$ the maximum \% fall after the second test (aftero placebo or clemastine), expressed as a \% of the fall after the first test. The percentage protection $\vec{\circ}$ indices for placebo and clemastine have been compared by paired $t$ test.

\section{Results}

The degree of airway obstruction before the first $c$ exercise challenge was similar on each study day (table 1) as were the initial values for PEFR and ${ }_{0}$ $\mathrm{FEV}_{1}$ before the second, post-inhalation, exercise test each time, although clemastine caused slight $\vec{c}$ bronchodilatation. There was a mean rise in $\mathbb{D}$ PEFR of $7.5 \%$ and FEV $_{1}$ of $9.5 \%$, both of which $\underset{\mathbb{D}}{\circ}$ were statistically significant, when the second 3 baseline values were compared with the initial baseline values on the clemastine day. On the $\overrightarrow{0}$ placebo day there was a small and insignificant 0 fall in the baseline between the first and second exercise tests.

The exercise tests, four for each patient, were closely matched both in terms of total oxygen consumption and total ventilation (table 2).

There was no significant difference in the degree $\stackrel{D}{\circ}$ of EIA between the initial control exercise tests $\overrightarrow{\overrightarrow{0}}$ on each study day. The mean falls in PEFR after initial exercise on saline and clemastine days were $27.0 \%$ and $26.4 \%$ respectively. The mean falls in FEV $_{1}$ were $25 \cdot 6 \%$ and $24 \cdot 2 \%$.

The individual responses to exercise challenge after drug inhalation are shown in table 3 . Saline $\times$ produced no significant effect on the $\%$ falls of $\frac{5}{3}$ either PEFR or $\mathrm{FEV}_{1}$, but clemastine inhalation gave a highly significant degree of protection against EIA. The mean fall in PEFR was reduced from $25.4 \%$ to $12.6 \%(p=0.0002)$ and that of FEV $_{1}$ from $22.0 \%$ to $12.2 \% \quad(p=0.004)$. All $\frac{D}{O}$ patients experienced less EIA after clemastine as measured by both indices used, with the exception $N$

Table 1 Lung function before exercise

\begin{tabular}{|c|c|c|c|c|c|c|}
\hline & \multicolumn{3}{|c|}{ PEFR (litres/min) } & \multicolumn{3}{|c|}{ FEV $V_{1}$ (litres BTPS) } \\
\hline & Saline & $p$ & Clemastine & Saline & $p$ & Clemastine \\
\hline Initial baseline & $399 \pm 22(78)$ & NS & $404 \pm 22(79)$ & $2 \cdot 53 \pm 0 \cdot 16(77)$ & NS & $2 \cdot 47 \pm 0 \cdot 16(76)$ \\
\hline p & NS & & 0.003 & NS & & 0.025 \\
\hline Second baseline & $394 \pm 24(77)$ & NS & $433 \pm 24(85)$ & $2 \cdot 38 \pm 0 \cdot 17(73)$ & NS & $2 \cdot 71 \pm 0 \cdot 21(82)$ \\
\hline
\end{tabular}

Second baseline values are those immediately before the second test each day-that is, 90 minutes after inhalation of saline or clemastine. Figures are mean values $\pm \mathrm{SE}$ ( $\%$ of predicted normal values in brackets). 
Table 2 Eight-minute exercise performance

\begin{tabular}{llll}
\hline Day & Test & $\begin{array}{l}\text { Total oxygen uptake } \\
(\mathrm{mmol}) *\end{array}$ & $\begin{array}{l}\text { Total ventilation } \\
(\text { litres BTPS })\end{array}$ \\
\hline Saline & 1 & $550 \pm 26$ & $360 \pm 14$ \\
& 2 & $551 \pm 25$ & $367 \pm 18$ \\
\hline Clemastine & 1 & $556 \pm 25$ & $349 \pm 12$ \\
& 2 & $549 \pm 26$ & $354 \pm 14$ \\
\hline
\end{tabular}

Results are mean values \pm SE.

*Multiply by $22 \cdot 4$ to convert to $\mathrm{ml}$.

Table 3 Percentage falls in PEFR and FEV ${ }_{1}$ after exercise preceded by inhalation of saline or clemastine

\begin{tabular}{|c|c|c|c|c|}
\hline \multirow[t]{2}{*}{ Patient } & \multicolumn{2}{|l|}{ Saline } & \multicolumn{2}{|c|}{ Clemastine } \\
\hline & $P E F R$ & $F E V_{1}$ & PEFR & $F E V_{1}$ \\
\hline 1 & $14 \cdot 5$ & $22 \cdot 4$ & $7 \cdot 9$ & $7 \cdot 1$ \\
\hline 2 & $29 \cdot 1$ & $28 \cdot 3$ & $20 \cdot 1$ & $5 \cdot 4$ \\
\hline 3 & $28 \cdot 9$ & $31 \cdot 5$ & 8.9 & $11 \cdot 5$ \\
\hline 4 & 29.6 & $30 \cdot 1$ & $17 \cdot 3$ & $19 \cdot 0$ \\
\hline 5 & $38 \cdot 8$ & $38 \cdot 8$ & $20 \cdot 1$ & $25 \cdot 8$ \\
\hline 6 & $23 \cdot 2$ & $13 \cdot 8$ & $16 \cdot 4$ & $16 \cdot 5$ \\
\hline 7 & $14 \cdot 1$ & $11 \cdot 4$ & $10 \cdot 4$ & $7 \cdot 3$ \\
\hline 8 & $23 \cdot 1$ & $13 \cdot 2$ & $1 \cdot 3$ & $6 \cdot 4$ \\
\hline 9 & $28 \cdot 6$ & $19 \cdot 3$ & $9 \cdot 2$ & $16 \cdot 7$ \\
\hline 10 & $24 \cdot 0$ & 10.9 & $14 \cdot 6$ & $6 \cdot 2$ \\
\hline Mean & $25 \cdot 4$ & $22 \cdot 0$ & $12 \cdot 6$ & $12 \cdot 2$ \\
\hline$\pm \mathbf{S E}$ & $2 \cdot 3$ & $3 \cdot 1$ & 1.9 & $2 \cdot 2$ \\
\hline
\end{tabular}

Paired $t$ test on $\log _{\mathrm{e}} \mathrm{a} / \mathrm{b}, \mathrm{p}=0.0002(\mathrm{PEFR})$ and $\mathrm{p}=0.004\left(\mathrm{FEV}_{1}\right)$.

of the $\mathrm{FEV}_{1}$ response of patient 6, who was the only non-atopic subject.

The mean percentage protection index for saline was $-3.0 \%$ for PEFR and $15 \cdot 2 \%$ for $\mathrm{FEV}_{1}$, indicating little placebo response for the group as a whole. The mean index for clemastine was $46.2 \%$ for PEFR and $\mathbf{4 7 \cdot 7 \%}$ for $\mathrm{FEV}_{1}$. Both values were significant compared with placcbo $(\mathrm{p}=0.003$ and 0.002 respectively).

Bronchodilatation, measured either in terms of absolute change in lung function or expressed as percentage improvement, did not correlate significantly with the difference in EIA between tests preceded by placebo or clemastine $(p>0.05$ for both PEFR and FEV 1 ).

\section{Discussion}

Recent studies on exercise-induced asthma have shown the importance of hyperventilation and airway cooling, ${ }^{12}$ but the link between heat loss from the airways and bronchospasm is not yet clear. Both neural (vagal) ${ }^{1}$ and chemical $^{2}$ mechanisms have been suggested. One possibility, which has been considered for many years, is that active mediator substances released from mast cells in the bronchi may be involved. ${ }^{11}$ There has been no direct evidence to support this theory. The fact that EIA is reduced when exercise is repeated at short intervals, even when lung function has returned to normal, might suggest that mediator stores become depleted and need time to be replenished.1112 Further indirect evidence is provided by the protective effect of sodium cromoglycate against EIA in many individuals, since this drug is thought to act by stabilising mast cells, ${ }^{13}$ and the close correlation between bronchial hyperreactivity to exogenous histamine and exercise. ${ }^{14}$

More recently, attempts have been made to look for mediators directly in peripheral blood during attacks of EIA. Histamine is the first substance to be so investigated, since sensitive enzymatic or fluorimetric assays are now available, but the reported findings are conflicting. ${ }^{15-17}$ An approach which has so far received little attention is the use of specific mediator antagonists to block EIA.

The study we report here has shown that clemastine significantly reduced EIA in our group of 10 patients. Some improvement in EIA was seen in all subjects, as assessed by PEFR and FEV , with the exception of the $F E V_{1}$ response of patient 6. Marked protection (protection index $>50 \%$ ) was seen in five subjects using PEFR and six using $\mathrm{FEV}_{1}$. No subject had a protection index above $50 \%$ with saline according to PEFR measurements, while only one did so according to

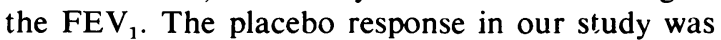
therefore low, and this, together with the uniform effect of clemastine, was responsible for the highly significant result. The degree of protection afforded by clemastine for the whole group is moderate, being slightly lower than that reported for methyl xanthines and sodium cromoglycate. and much lower than that reported for salbutamol, ${ }^{9} 10$ but in the latter study, the protection index for placebo was higher than our own at $25 \%$. We consider that the design of our trial has allowed genuine responses to be more clearly distinguished from placebo effects and the natural variation of EIA itself.

We think it unlikely that clemastine affected EIA in any way other than by blocking the action of histamine released during exericse. Although significant bronchodilatation was produced, this was of a much smaller order than we have found in patients recovering from acute severe asthma, ${ }^{3}$ and the improvement in lung function did not correlate individually with protection against EIA. Similarly, clemastine is unlikely to have blocked vagal reflex bronchoconstriction. Although many antihistamines possess anticholinergic activity. 
clemastine has been shown to be ineffective in preventing methacholine-induced bronchoconstriction in doses similar to those used in the present study, and which were able to block the effects of inhaled histamine. ${ }^{4}$ Moreover, such an explanation would not accord with the variable effect of large doses of atropine or ipratropium bromide on EIA ${ }^{9} 18$ Another possible means by which clemastine might reduce EIA relates to the in vitro studies of Lichtenstein and Gillespie. ${ }^{19}$ These workers found that many $\mathrm{H}_{1}$ antagonists in low doses inhibit antigen-induced histamine release from human basophils. Whether this "cromoglycate-like" effect has any relevance in vivo is unknown.

There have been few other studies of conventional antihistamines in EIA. McNeill and coworkers ${ }^{11}$ reported no benefit in five subjects from an intramuscular injection of mepyramine maleate given 15-30 minutes before exercise, and Sly and his colleagues ${ }^{20}$ refer to their own unpublished observations which also showed no apparent effect, although no details were given. Zielinski and Chodosowska ${ }^{21}$ found significant improvement in EIA after thiazinamium, $50 \mathrm{mg}$, given intramuscularly 30 minutes before exercise, while atropine, $2 \mathrm{mg}$ intravenously five minutes before exercise had no significant effect. However, thiazinamium produced a mean improvement of $35 \%$ in lung function, which was not seen after atropine at the time interval used, and this makes the results difficult to interpret. There have been no previous reports of the effect of inhaled antihistamines on EIA. Inhalation allows a greater amount of active drug to reach the airways than is possible after parenteral administration unless undesirable side effects, particularly sedation, are produced.

We believe that the effect of the $\mathrm{H}_{1}$ antagonist clemastine on EIA indicates that histamine is involved in its pathogenesis in the majority of patients. The effect of histamine could theoretically be a direct one on smooth muscle or could occur through vagal reflex mechanisms if bronchial irritant receptors were activated by local histamine release. Four of the patients in this study have been challenged after the administration of ipratropium bromide, an anticholinergic agent, and two showed a marked reduction of EIA after a relatively low dose of $0 \cdot 1 \mathrm{mg}$ by inhalation. The other two had significant inhibition of EIA only after a high dose, $1.0 \mathrm{mg}$. This suggests that histamine may have both direct and reflex effects, which vary in degree between patients. The alternative theory, that both drugs are merely acting as bronchodilators in preventing EIA seems unlikely for the reasons already discussed. Als clemastine caused minimal bronchodilatation in this study, and bronchodilatation is commonly seen after low doses of ipratropium bromide, with out protection against EIA.

Clemastine did not inhibit EIA completely, andwhile this may be because of the dosage given, it is likely that other mediator substances releasectw from mast cells may be involved in addition to histamine. When new and specific antagonists tor these mediators become available, their contribu tion to EIA may be more readily assessed.

We would like to thank Dr IA Campbell, Dr $\mathrm{BH}^{\mathrm{v}}$ Davies, Dr GS Kilpatrick, and Dr AP Smith for? allowing us to study patients under their care, $\vec{c}$ and Mrs PH Roberts for typing the manuscript.

\section{References}

1 Zeballos RJ, Shturman-Ellstein R, McNally JF $\vec{\bullet}$ Hirsch JE, Souhrada JF. The role of hyperventila-o0 tion in exercise-induced bronchoconstriction. $A m^{\circ}$ Rev Respir Dis 1978; 118:877-84.

2 Deal EC, McFadden ER, Ingram RH, Strauss $\mathrm{RH}$, Jaeger JJ. Role of respiratory heat exchange in production of exercise-induced asthma. $J$ Applo Physiol 1979; 46:467-75.

3 Nogrady SG, Hartley JPR, Handslip PDJ, Hurst NP. Bronchodilatation after inhalation of theo antihistamine clemastine. Thorax 1978; 33:479-82..

4 Nogrady SG, Bevan C. Inhaled antihistamines: bronchodilatation and effects on histamine-0 and methacholine-induced bronchoconstriction. Thorax 1978; 33:700-4.

5 Miller GJ, Davies BH, Cole TJ, Seaton A. Com $\frac{0}{x}$ parison of the bronchial response to running and cycling in asthma using an improved definition? of the response to work. Thorax 1975: 30:306-11.

6 Hartley JPR, Charles TJ, Seaton A. Betamethasone valerate inhalation and exercise-induced asthma in adults. $\mathrm{Br} J$ Dis Chest 1977; 71:253-8. 긍

7 Lange-Andersen K, Shephard RJ, Denolin H $>$ Varnauskas E, Masironi R. Fundamentals of exercise testing. Geneva: World Health Organis- ज్ ation, 1971.

8 Cotes JE. Lung function: assessment and applica- N tion in medicine. Third edition. Oxford: Blackwell Scientific, 1975.

9 Godfrey S, König P. Inhibition of exerciseinduced asthma by different pharmacological path-을 ways. Thorax 1976; 31:137-43.

10 Wallace D, Grieco MH. Double-blind, cross-over $\stackrel{+}{-}$ study of cromolyn sodium inhibition of exercise- $\frac{T}{T}$ induced bronchospasm in adults. Ann Allergy $\underset{\mathbb{D}}{\stackrel{O}{D}}$ 1976; 37:153-63.

11 McNeill RS, Nairn JR, Millar JS, Ingram CG. Exercise-induced asthma. $Q J$ Med 1956; 35:5567. 
12 Edmunds AT, Tooley M, Godfrey S. The refractory period after exercise-induced asthma: its duration and relation to the severity of exercise. Am Rev Respir Dis 1978; 117:247-54.

13 Davies SE. Effect of disodium cromoglycate on exercise-induced asthma. $\mathrm{Br} \mathrm{Med} J \mathrm{~J}$ 1968; 3:593-4.

14 Anderton RC Cuff MT, Frith PA et al. Bronchial responsiveness to inhaled histamine and exercise. J Allergy Clin Immunol 1979; 63:315-20.

15 McFadden ER, Soter NA. A search for chemical mediators of immediate hypersensitivity and humoral factors in the pathogenesis of exerciseinduced asthma. In: Lichtenstein LM, Austen KF (eds). Asthma: physiology, immunopharmacology and treatment. New York: Academic Press, 1977:351-64.

16 Ferris L, Anderson SD, Temple DM. Histamine release in exercise-induced asthma. $\mathrm{Br}$ Med $\mathrm{J}$ 1978; 1:1697.
17 Charles TJ, Hartley JPR, Seaton A, Taylor WH, Westwood A. Arterial histamine in exerciseinduced asthma. Clin Sci Mol Med 1979; 56:8P.

18 Thomson NC, Patel KR, Kerr JW. Sodium cromoglycate and ipratropium bromide in exercise-induced asthma. Thorax 1978; 33:694-9.

19 Lichtenstein LM, Gillespie E. The effects of the $\mathrm{H}_{1}$ and $\mathrm{H}_{2}$ antihistamines on "allergic" histamine release and its inhibition by histamine. J Pharmacol Exp Ther 1975; 192:441-50.

20 Sly RM, Heimlich EM, Busser RJ, Strick L. Exercise-induced bronchospasm: Effect of adrenergic or cholinergic blockade. J Allergy 1967; 40:93-9.

21 Zielinski J, Chodosowska E. Exercise-induced bronchoconstriction in patients with bronchial asthma: its prevention with an antihistaminic agent. Respiration 1977; 34:31-5. 